\title{
Factors that influence the outcome of primary pulmonary hypertension
}

\author{
ADRIAN ROZKOVEC, * PATRICIA MONTANES, $†$ CELIA M OAKLEY \\ From the Department of Clinical Cardiology, Department of Medicine, Hammersmith Hospital, London
}

SUMMARY Factors predicting life expectancy in primary pulmonary hypertension have not been well defined. Thirty four cases of primary pulmonary hypertension that had been followed up until death or for at least five years were reviewed retrospectively. Patients were divided into three groups: 18 patients who died within five years of presentation to hospital; 12 who survived more than five years; and four who improved and who lived for more than five years. The age at onset was similar in the three groups and, like symptoms and sex, did not predict life expectancy. Right heart failure during the course of the disease was associated with a poor outcome. Radiographic evidence of cardiac enlargement and evidence of right heart strain on electrocardiogram at presentation was also predictive of survival for $<$ five years. Pulmonary arteriolar resistance was higher and cardiac output lower in those with the shortest survival times. There was no relation between pulmonary artery pressure and length of survival. Systemic resistance varied directly with pulmonary resistance and served to maintain systemic pressure. Presentation in or after pregnancy and patency of the foramen ovale were associated with longer survival. In four patients there was evidence of regression of the disease by cardiac catheterisation and lung histology.

Primary pulmonary hypertension is a heterogenous condition in which life expectancy varies widely.

Primary pulmonary hypertension is a rare disease. The condition was well known to Paul Wood and the clinical features were meticulously presented by him in 1952, but credit for the first full description is usually given to Dresdale et al. ${ }^{1}$ The pathology was reviewed by Brenner in 1935. In 1970 Wagenvoort and Wagenvoort in their detailed multicentre study of lung histology put forward the criteria necessary for complete diagnosis. ${ }^{2}$ The incidence is at most one in $\mathbf{2 0 0}$ of all cases of cardiac disease that go to catheterisation. ${ }^{34}$

There have been few follow up studies of sufficient size for valid conclusions to be reached on the factors predicting outcome. ${ }^{356}$ The largest

Requests for reprints to Dr A Rozkovec, Department of Cardiology, Bristol Royal Infirmary, Bristol BS2 8HW.

Present addresses: "Department of Cardiology, Bristol Royal Infirmary, Marlborough Street, Bristol BS2 8HW; †Department of Pediatrics, Baylor College of Medicine, 1200 Moursund Avenue, Houston, Texas 77030.

Accepted for publication 6 January 1986 reviews have been multicentre ones, ${ }^{257}$ or have been cases collected from published reports. ${ }^{8}$ The identification of risk factors might provide a greater understanding of pathophysiology and ultimately help in treatment.

The haemodynamic, electrocardiographic, and chest $x$ ray findings accompanying clinical deterioration have been reported, ${ }^{35}$ but the relation of these changes to life expectancy has not. Right heart failure usually occurs with time. Some patients with primary pulmonary hypertension have a patent foramen ovale due to persistently raised right atrial pressure. There is experimental evidence that such a shunt can prevent sudden death. ${ }^{910}$ We examined the prognostic importance of right heart failure and of the presence of a patent foramen ovale.

The influence of associated disease on outcome is uncertain. Pulmonary hypertension is found in association with various connective tissue disorders $^{1112}$ in the absence of interstitial lung damage, but in most patients with pulmonary hypertension there is no evidence of another disease. The preponderance of females in both conditions is well 
known. ${ }^{235}$ Oral contraception ${ }^{1314}$ and pregnancy ${ }^{15}$ have been linked with progressive pulmonary vascular disease-both to the apparent onset of primary pulmonary hypertension and to development of the Eisenmenger syndrome in ventricular septal defect. Presentation in right heart failure towards the end of pregnancy or post partum is well recognised and generally considered to carry a poor immediate and long term outlook. ${ }^{15}$ This was not our experience. Finally, survival from time of presentation or onset of symptoms is variable ${ }^{38}$ and reports of spontaneous regression have been rare $^{81617}$ except after ingestion of anorectic drugs. ${ }^{6}$ Regression may occur more frequently than supposed.

\section{Patients and methods}

The records of all 34 patients with a diagnosis of primary pulmonary hypertension attending Hammersmith Hospital between 1961 and 1981 were traced. All of them had been followed until death or had survived for at least five years from the time of presentation to a hospital. Those who had been followed up for less than five years and who were still alive were not included in this series.

Pulmonary hypertension is deemed to be idiopathic when all known causes have been excluded. We believe that pulmonary perfusion must be assessed before idiopathic pulmonary hypertension can be diagnosed. In a retrospective series of patients with primary pulmonary hypertension in which lung histology was available, such investigations had not been universally applied, and most of those who were misdiagnosed had thromboembolic hypertension. ${ }^{2}$ The criteria for diagnosis and the number of tests used were: right ventricular hypertrophy on the electrocardiogram in the absence of known cause (34); raised pulmonary artery pressure and normal capillary wedge or left ventricular filling pressure (34); pulmonary angiogram consistent with primary pulmonary hypertension (29); normal ventilation perfusion lung scan (25); consistent lung histology (5); $M$ mode echocardiogram (13). No patient had taken oral contraceptives before presentation and none had been taking anorectic medication at any stage.

Seven patients had more than one cardiac catheterisation. All had had a ventilation perfusion scan or pulmonary angiogram, and most had had both. Nineteen of 25 perfusion lung scans were normal and six showed only minor perfusion abnormalities. $^{1819}$ Pulmonary angiograms showed no evidence of pulmonary emboli. Lung histology was studied at necropsy. The $M$ mode echocardiogram recordings had features consistent with idiopathic pulmonary hypertension in every case. ${ }^{20}$
Follow up was measured from the time of presentation to hospital and ranged from five to 28 years; follow up at Hammersmith Hospital was eight months to 14 years. Data were compiled from our records and those of the referring physicians. Details of the history, examination, electrocardiogram, and chest $x$ ray within the first six months of hospital attendance were available for every subject. Whenever findings were abnormal during this period they were recorded as being those at presentation. Further clinical details were obtained from the patient when possible. Overt right heart failure was defined as a combination of a raised jugular venous pressure, enlargement of the liver, and peripheral oedema. The resting electrocardiogram was analysed for right atrial strain, frontal axis, and evidence of right ventricular hypertrophy. The criteria for right ventricular hypertrophy were fulfilled if two or more of the following four conditions were met: $R$ wave in $\mathrm{V} 1>0.7 \mathrm{mV}, S$ wave in $\mathrm{V} 1<0.2 \mathrm{mV}$, sum of the amplitudes of the $R$ wave in $V 1$ and larger of the $S$ waves in V5 or V6>1.05 mV, and $R$ wave in aVR $>0.5 \mathrm{mV}^{21}$ Right axis deviation was defined as a mean frontal $Q R S$ axis greater than $+90^{\circ}$. Chest $x$ rays were assessed by one observer and a radiologist aware of the likely diagnosis, but without knowledge of individual clinical courses. Analysis was subjective and for right ventricular enlargement was based on the lateral view. For the size of the main pulmonary artery, the posterior anterior projection was used. No patient had radiologically detectable interstitial lung disease.

Further investigations, especially cardiac catheterisations, were often performed after the first six month period. Catheterisation was always carried out with the patient in the fasting supine resting state. Assumed oxygen consumption was used to calculate cardiac output in all but three cases. Existence of a right to left shunt at atrial level was based on catheter patency and desaturation of left atrial blood. We excluded subjects in whom this was secondary to an atrial septal defect rather than a patent foramen ovale. ${ }^{22}$

Patients were divided into three groups according to their clinical course: group I, 18 who died within five years of presentation; group II, 12 patients who survived for longer than five years; and group III, four patients in whom there was evidence of regression. The survival time was examined in relation to associated conditions and to the haemodynamic data in an attempt to identify significant prognostic factors. One tailed Fisher's exact probability test and Student's $t$ test were applied where appropriate. Linear regression analysis and Spearman rank correlation coefficient were also used. ${ }^{23}$ Statistical significance was taken as $\mathbf{p}<0.05$. 


\section{Results}

There was no relation between age at presentation and mean survival (Table 1). The ratio of females to males was significantly lower for those aged $\geqslant 45$ at presentation than for those $<45$ at presentation $(p<0.01)$. Twenty six of the 34 patients studied were female. The most frequent symptoms when the patients were first seen at hospital were breathlessness $(100 \%)$, syncope or dizziness $(50 \%)$, palpitation $(11.8 \%)$, and exertional chest pain $(5.9 \%)$. The mean age at onset of symptoms was 33,30, and 27 years, for groups I, II, and III respectively. Seven were children aged <16; the youngest was 18 months old.

Table 2 summarises the initial clinical features of the three groups. Right ventricular failure at presentation was significantly more common in group I than in group II $(\mathrm{p}<0.05)$. Ascites was present in $50 \%$ of those in failure. All patients in group I eventually developed signs of right heart failure, and no deaths were sudden. Only one patient in group II presented in right heart failure, but seven subsequently developed this complication and five of them died. Two of this group are alive; both have a patent foramen ovale. Clinical evidence of right ventricular failure was examined in relation to chest $x$ ray and electrocardiographic findings. Only right ventricular enlargement and two of the three chosen electrocardiographic features of ventricular

Table 1 Sex and age at presentation and relation to survival

\begin{tabular}{lccccc}
\hline Age & Number & $\%$ & \multicolumn{2}{l}{ Sex } & \multicolumn{2}{c}{$\begin{array}{l}\text { Mean survival } \\
\text { time }(y r)\end{array}$} \\
\cline { 3 - 5 } & & & $F$ & $M$ & \\
\hline $0-15$ & 7 & $20 \cdot 6$ & 6 & 1 & $8 \cdot 7$ \\
$16-45$ & 19 & 55.9 & 17 & 2 & 7.9 \\
$>45$ & 8 & 23.5 & 3 & 5 & 4.9 \\
Total & 34 & 100 & 26 & 8 & $7 \cdot 3$ \\
& & & $(76 \%)$ & $(24 \%)$ & \\
\hline
\end{tabular}

overload were present to a significantly greater degree in those who died within five years than in those who did not. All these features remained unchanged or progressed in the patients of groups I and II who died. There was little response to diuretics and only one patient was treated with digoxin. All were put on warfarin and none was treated with vasodilators. In contrast, two of the four patients in group III were originally in heart failure; one recovered (case 1) and in another (case 2) there was a long period of stable congestive heart failure.

Table 3 shows haemodynamic data at rest. There were no significant differences between the three groups for mean right atrial pressure, right ventricular filling pressure, and peak systolic and mean pulmonary artery pressure, although all these variables were higher in groups I and II than in group III. Left ventricular filling pressure (measured directly in six) was greater and cardiac output lower in those who survived $<5$ years. Pulmonary arteriolar resistance and systemic vascular resistance were lower in those in whom the disease regressed than in those who died within five years of presentation. There was a direct linear relation between pulmonary arteriolar resistance and systemic resistance $(r=0.66, \mathrm{p}<0.0005)$ for patients in all three groups (Fig. 1).

We used Spearman's rank correlation (one tailed) to analyse the initial haemodynamic values for individual patients in relation to survival time from presentation. Cardiac ouput was directly related to survival $(p<0.0005)$. The longer the survival, the lower the pulmonary arteriolar resistance $(<0.005)$, systemic vascular resistance $(p<0.001)$, and right ventricular end diastolic pressure $(p<0.025)$. Correlations for mean systemic, right atrial, and pulmonary artery pressures were not significant.

Repeat catheterisations were performed in three patients in group II and all four in group III. In the group II patients (Fig. 2) there was evidence of progression with a rise in total pulmonary vascular

Table 2 Clinical features at time of first presentation

\begin{tabular}{|c|c|c|c|c|}
\hline Clinical feature & $\underset{(\%)}{\text { Group } I(n=18)}$ & $\underset{(\%)}{\text { Group } I I(n=12)}$ & $\begin{array}{l}\text { Group III }(n=4) \\
(\%)\end{array}$ & p value (I vs $I I+I I I)$ \\
\hline $\begin{array}{l}\text { Examination: } \\
\text { Tricuspid regurgitation } \\
\text { Right ventricular added sound } \\
\text { Overt right heart failure }\end{array}$ & $\begin{array}{l}27 \cdot 7 \\
50 \cdot 0 \\
44 \cdot 4\end{array}$ & $\begin{array}{c}0 \\
25 \cdot 0 \\
8 \cdot 3\end{array}$ & $\begin{array}{l}50 \\
50 \\
50\end{array}$ & $\begin{array}{l}\text { NS } \\
\text { NS } \\
\text { NS }\end{array}$ \\
\hline $\begin{array}{l}\text { Electrocardiogram: } \\
\text { Right ventricular hypertrophy } \\
\text { Right axis deviation } \\
\text { Right atrial strain }\end{array}$ & $\begin{array}{c}100 \\
100 \\
94 \cdot 4\end{array}$ & $\begin{array}{l}83 \cdot 3 \\
66 \cdot 6 \\
25 \cdot 0\end{array}$ & $\begin{array}{r}75 \\
100 \\
50\end{array}$ & $\begin{array}{l}\text { NS } \\
<0.05 \\
<0.0005\end{array}$ \\
\hline $\begin{array}{l}\text { Chest } x \text { ray: } \\
\text { Right ventricular enlargement } \\
\text { Pulmonary artery dilatation }\end{array}$ & $\begin{array}{l}100 \\
100\end{array}$ & $\begin{array}{l}66 \cdot 6 \\
100\end{array}$ & $\begin{array}{r}50 \\
100\end{array}$ & $\begin{array}{l}<0.01 \\
\text { NS }\end{array}$ \\
\hline
\end{tabular}


Table 3 Haemodynamic features (mean (1SD)) at first cardiac catheterisation

\begin{tabular}{|c|c|c|c|c|c|c|}
\hline & \multicolumn{3}{|l|}{ Groups } & \multicolumn{3}{|l|}{$p$ value } \\
\hline & $I(n=18)$ & $I I(n=12)$ & $I I I(n=4)$ & $I$ vs $I I$ & $I$ vs $I I I$ & $I I$ vs $I I I$ \\
\hline $\begin{array}{l}\text { Survival time from presentation (yr) } \\
\text { Catheter time from presentation }(\mathrm{yr}) \\
\overline{\mathrm{RA}}(\mathrm{mm} \mathrm{Hg}) \\
\mathrm{RVEDP}(\mathrm{mm} \mathrm{Hg}) \\
\text { SPAP }(\mathrm{mm} \mathrm{Hg}) \\
\mathrm{PA}(\mathrm{mm} \mathrm{Hg})\end{array}$ & $\begin{array}{c}2 \cdot 68(1 \cdot 13) \\
1 \cdot 44(1 \cdot 20) \\
7 \cdot 56(3 \cdot 55) \\
12 \cdot 29(4 \cdot 38)^{\star} \\
97 \cdot 44(19 \cdot 73) \\
63 \cdot 89(12 \cdot 31)\end{array}$ & $\begin{array}{c}9.67(4 \cdot 87) \\
4 \cdot 83(4 \cdot 95) \\
8 \cdot 00(4 \cdot 63) \\
11 \cdot 00(5 \cdot 91) \\
93.33(32 \cdot 59) \\
60 \cdot 75(22 \cdot 43)\end{array}$ & $\begin{array}{r}18 \cdot 75(6 \cdot 40) \\
5 \cdot 25(7 \cdot 23) \\
6 \cdot 25(4 \cdot 65) \\
8 \cdot 75(5 \cdot 68) \\
81 \cdot 50(32 \cdot 22) \\
53 \cdot 75(13 \cdot 87)\end{array}$ & $\begin{array}{l}<0.0005 \\
<0.005 \\
\text { NS } \\
\text { NS } \\
\text { NS } \\
\text { NS }\end{array}$ & $\begin{array}{l}<0.0005 \\
<0.025 \\
\text { NS } \\
\text { NS } \\
\text { NS } \\
\text { NS }\end{array}$ & $\begin{array}{l}<0 \cdot 0005 \\
\text { NS } \\
\text { NS } \\
\text { NS } \\
\text { NS } \\
\text { NS }\end{array}$ \\
\hline $\begin{array}{l}\overline{\text { PCW }} / \text { LVEDP }(\mathrm{mm} \mathrm{Hg}) \\
\text { CO }(1 / \mathrm{min}) \\
\text { PAVR (U) } \\
\overline{S A}(\mathrm{~mm} \mathrm{Hg}) \\
\text { SVR }(\mathrm{U})\end{array}$ & $\begin{array}{c}8.33(2.89) \\
2.77(0.44) \\
20.66(4.84) \\
83.67(11 \cdot 15) \\
28.33(6.50)\end{array}$ & $\begin{array}{l}6 \cdot 42(2 \cdot 87) \\
3.56(1 \cdot 14) \\
16 \cdot 95(9 \cdot 35) \\
87.92(15 \cdot 10) \\
24 \cdot 26(7 \cdot 95)\end{array}$ & $\begin{array}{l}5 \cdot 25(2.06) \\
4.30(1.91) \\
12 \cdot 22(4.97) \\
79 \cdot 50(10 \cdot 79) \\
18.58(5.48)\end{array}$ & $\begin{array}{l}<0.05 \\
<0.01 \\
\text { NS } \\
\text { NS } \\
\text { NS }\end{array}$ & $\begin{array}{l}<0.05 \\
<0.005 \\
<0.005 \\
\text { NS } \\
<0.01\end{array}$ & $\begin{array}{l}\text { NS } \\
\text { NS } \\
\text { NS } \\
\text { NS } \\
\text { NS }\end{array}$ \\
\hline
\end{tabular}

$\overline{\mathrm{RA}}$, mean right atrial pressure; RVEDP, right ventricular end diastolic pressure; SPAP, systolic pulmonary artery pressure; $\overline{\mathrm{PA}}$, mean pulmonary artery pressure; $\overline{P C W} / L$ VEDP, mean pulmonary capillary wedge pressure/left ventricular end diastolic pressure; CO, cardiac output; PAVR, pulmonary arteriolar vascular resistance; $\overline{\mathrm{SA}}$, mean systemic pressure; SVR, systemic vascular resistance.

$\star_{n}=17$.

resistance and pulmonary artery pressure and fall in cardiac output. In contrast, there was clear improvement in three out of the four patients in group III (Fig. 3) with a fall in total pulmonary vascular resistance and pulmonary artery pressure and rise in cardiac output.

In the fourth patient (case 2) pulmonary artery pressure and cardiac output both fell and the haemodynamic changes were accompanied by clinical deterioration and chronic right ventricular failure. She died twelve years later of salmonella infection of her chronic ascites. Postmortem histology showed

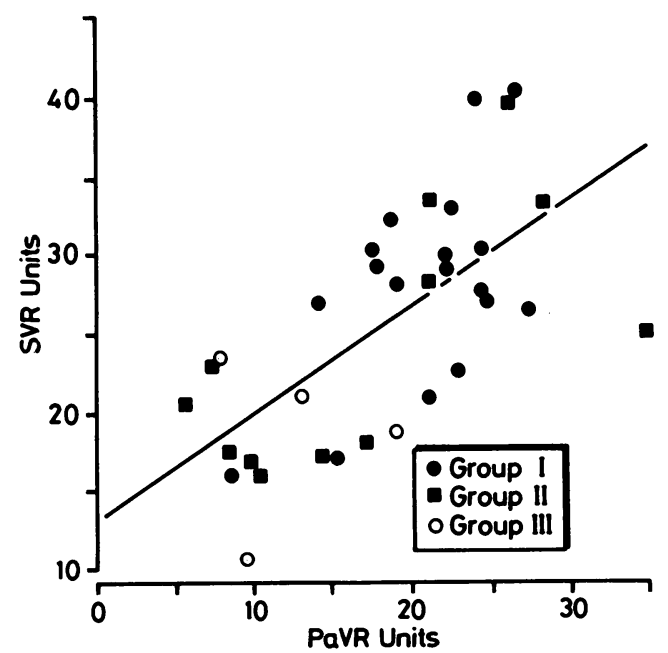

Fig. 1 Resting haemodynamic data on first catheterisation in 34 patients with primary pulmonary hypertension. SVR, systemic vascular resistance; $P a V R$, pulmonary arteriolar vascular resistance. Linear regression equation: $y=13 \cdot 14+0.687 x ; r=0.66 ; p=<0.0005$. only grade 1 changes on the Heath classification ${ }^{24}$ after she had survived more than a decade in heart failure but with a near normal pulmonary artery pressure.

Heart size and electrocardiographic evidence of right ventricular hypertrophy decreased in the three patients who did well. In two of these (cases 3 and 4) symptoms first appeared during and after pregnancy. Case 4 was given a trial of prenylamine and domiciliary oxygen soon after diagnosis and continued to take prenylamine for one year. Case 1, the
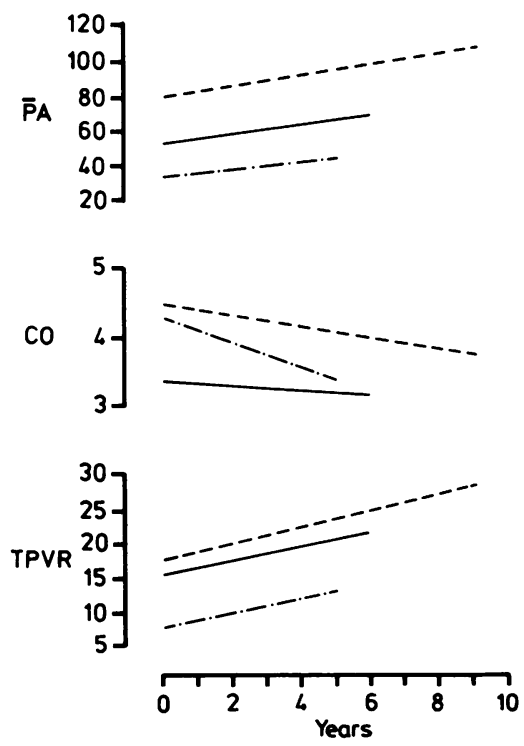

Fig. 2 Resting haemodynamic data in the three patients of group II who had repeat cardiac catheterisation. $\bar{P} A$, mean pulmonary artery pressure $(\mathrm{mm} \mathrm{Hg}) ; \mathrm{CO}$, cardiac output (l/min); TPVR, total pulmonary vascular resistance (units). 


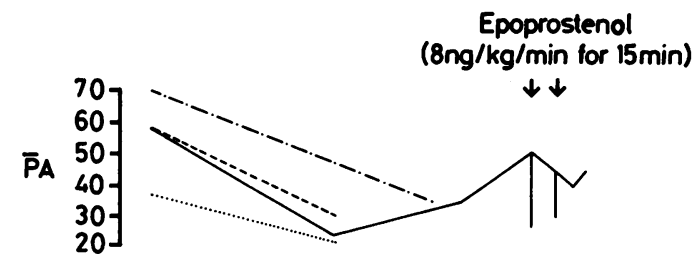

Table 4 Relation of clinical and haemodynamic features to survival

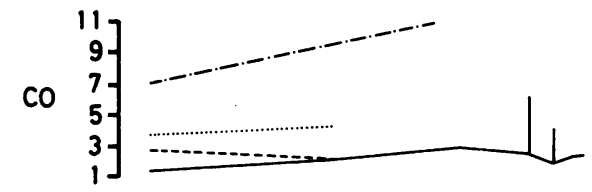

\begin{tabular}{llll}
\hline & \multicolumn{2}{l}{ Survival } & \\
\cline { 2 - 4 } & $\begin{array}{llll}<5 y r \\
(n=18)\end{array}$ & $\begin{array}{l}>5 y r \\
(n=16)\end{array}$ & p value \\
\hline Familial disease & 1 & 1 & NS \\
Connective tissue disease & 3 & 0 & NS \\
$\begin{array}{l}\text { Pregnancy } \\
\text { Patent foramen ovale }\end{array}$ & 0 & 5 & $<0.02$ \\
$\begin{array}{l}\text { Right heart failure at } \\
\text { presentation }\end{array}$ & 0 & 4 & $<0.05$ \\
$\begin{array}{l}\text { Right heart failure at some } \\
\text { stage }\end{array}$ & 8 & 3 & NS \\
\hline
\end{tabular}

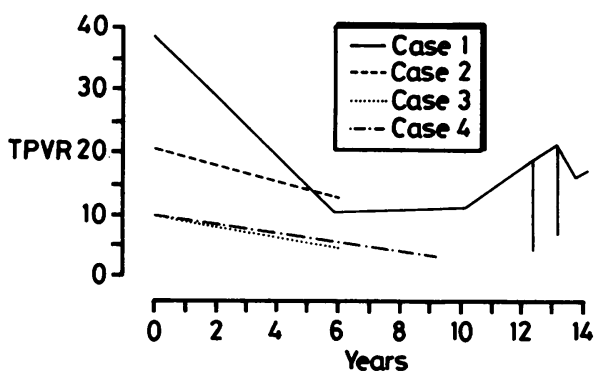

Table 5 Mean survival after presentation and factors that may be associated with outcome

\begin{tabular}{lccc}
\hline Factor & Number & $\%$ & $\begin{array}{c}\text { Mean survival } \\
(y r)\end{array}$ \\
\hline Familial disease & 2 & 5.9 & 6 \\
Connective tissue & & & \\
$\quad$ disease & 3 & $8 \cdot 8$ & 3.4 \\
Pregnancy & 5 & $14 \cdot 7$ & $14 \cdot 2$ \\
Patent foramen ovale & 4 & $11 \cdot 8$ & 11.5 \\
No related factors & 20 & $58 \cdot 8$ & 5.5 \\
All patients & 34 & 100 & 7.3 \\
\hline
\end{tabular}

Fig. 3 Resting haemodynamic data in patients in group III. $\bar{P} A$, mean pulmonary artery pressure $(\mathrm{mm} \mathrm{Hg}) ; C O$, cardiac output (l/min); TPVR, total pulmonary vascular resistance (units). Data on patient 1 are indexed per $m^{2}$ because she was first studied as an adolescent.

subject of a previous report, ${ }^{16}$ deteriorated again after a pregnancy and spontaneous abortion (Fig. 3) but she has subsequently improved, though pulmonary artery pressure remains raised. Epoprostenol (prostacyclin), a powerful vasodilator, was infused at a dose of $8 \mathrm{ng} / \mathrm{kg} / \mathrm{min}$ for 15 minutes, and on both occasions produced short term haemodynamic improvement. She is almost symptom free, as are the other two. None of group III had a patent foramen ovale.

In five cases lung histology was traced. Two showed Heath grade 3 changes ${ }^{24}$; one each in group I and II. A further two, both in group I, had grade 5 changes. In the fifth patient from group III, case 2 described above, there was evidence of a fall in pulmonary artery pressure for at least eight years before death and only grade 1 changes. Three patients had associated connective tissue disease (systemic sclerosis, systemic lupus erythematosus, and rheumatoid arthritis). In two of these histological assessment was available; neither had evidence of pulmonary vasculitis.

Tables 4 and 5 list associated factors that might influence survival. Two patients had a relative with

proven primary pulmonary hypertension. The three patients with connective tissue disease lived for $<5$ years after presentation. The outcome was significantly better when pulmonary hypertension first appeared during pregnancy $(p<0.02)$. All five had symptoms towards the end of pregnancy. None went into right heart failure. Two had had one previous uneventful pregnancy. In one patient (case 1) there had been an improvement until her spontaneous abortion. Although right heart failure at presentation was not predictive of a poor outcome, an episode of documented right heart failure at some stage during follow up was associated with poor prognosis $(\mathrm{p}<0.01)$. Again, case 1 was an exception. The presence of a patent foramen ovale improved prognosis $(p<0.05)$.

\section{Discussion}

The diagnosis of primary pulmonary hypertension is reached by exclusion. Five patients in this series did not have pulmonary angiograms. Most perfusion lung scans were normal. In primary pulmonary hypertension minor perfusion defects accompanied by normal ventilation on lung scan are sometimes seen, ${ }^{1819}$ without histological evidence of pulmonary emboli ${ }^{25}$ whereas chronic thromboembolic pulmonary hypertension always causes major defects. We made every attempt to include only 
those patients who fulfilled current criteria for pulmonary hypertension of unknown cause. ${ }^{825}$

The diagnosis can only be established with certainty by examination of a representative lung biopsy specimen of adequate $\operatorname{size}^{2627}$; this was achieved in five patients. During the period of this study there were four patients with pulmonary veno-occlusive disease; in two the diagnosis was confirmed by lung biopsy and in all it was subsequently confirmed at necropsy. Six patients had thromboembolic pulmonary hypertension. These 10 patients were excluded from the series.

All but two of the patients were first catheterised when aged $>17$ years. Onset in childhood is less common. ${ }^{28}$ The sex distribution, with a predominance of females after the menarche is similar to that reported in other series. ${ }^{2} 5$ The reasons for this are unknown ${ }^{8}$ and this observation is as true of familial as of non-familial primary pulmonary hypertension. ${ }^{29}$ The finding that a greater proportion of male patients had late onset disease is supported by a previous study. ${ }^{7}$ Again, the reason for this is unknown.

Age at presentation to hospital rather than onset of symptoms was taken as our reference point, because onset is inevitably poorly defined in such a slowly progressive condition. There was no relation between age at presentation and mean survival, and this accords with previous work. ${ }^{3}$ The frequency of symptoms was similar to those already reported..$^{3812}$ Breathlessness is usually the first and almost universal complaint. ${ }^{3812}$ No patients in our series gave a history consistent with digital vasospasm but not all can be assumed to have been directly questioned about this. The onset of symptoms occurred slightly earlier in those surviving for $>5$ years. Survival in adults is regarded as being independent of the age of onset. ${ }^{23}$

Outcome was poor when clinical right heart failure was evident at presentation to hospital or developed subsequently. The association of right heart failure with mortality is as true of primary pulmonary hypertension 530 as it is of pulmonary hypertension associated with ingestion of aminorex ${ }^{6}$ and thromboembolic disease. ${ }^{31}$ Non-invasive measures of right ventricular load and right ventricular size and mass from the electrocardiogram and $x$ ray were no more useful for predicting outcome than were clinical features in those with right heart failure. The pulmonary artery size was unhelpful and is known not to correlate with pulmonary artery pressure in this condition. ${ }^{32}$

The haemodynamic features in the three groups reflected the nature of the disease course and outcome (Table 3). The patients of group II were catheterised later in their course than those of group I
(Table 3) and their catheter findings indicated more advanced disease. Nevertheless, pulmonary arteriolar resistance was less in patients surviving $>5$ years from presentation. Pulmonary arteriolar resistance was inversely related to cardiac output, in keeping with the effects of increased afterload on right ventricular function,,$^{33} 34$ and pulmonary artery pressure was not significantly different in the three groups. This has been the usual finding because most patients are not catheterised before an advanced stage of their disease is reached. ${ }^{8}$ In the few with less advanced disease, pulmonary artery pressure increased with time (Fig. 2). Mean right atrial pressure and right ventricular filling pressure, indices of right ventricular preload, were lower in those who improved than in those who died within five years. There was no difference between groups I and II, perhaps because of the diuretics used to treat patients with overt heart failure. Furthermore, haemodynamic measurements are known to be labile in this condition, and presumably reflect spontaneous variation in pulmonary vascular tone and right ventricular function. ${ }^{35}$ In the group as a whole, increased right ventricular afterload, a low cardiac output, and raised right ventricular filling pressure were of most significance in predicting a poor outcome. As expected the level of pulmonary artery pressure was unrelated to outcome.

Little attention has been paid to the systemic circulation in this condition. The lower the cardiac output the higher the systemic resistance. No important pathological changes are seen in the resistance vessels of the systemic circulation in primary pulmonary hypertension. Selective vasodilatation of the pulmonary circulation is accompanied by a fall in systemic resistance as cardiac output rises. ${ }^{83}$ It follows that the systemic changes are secondary to those in the lung vascular bed. The compensatory changes in systemic resistance with alteration in cardiac output serve to maintain a constant blood pressure, as in other physiological settings. Not surprisingly, systemic and pulmonary arteriolar resistance were closely and directly related (Fig. 1).

On average, left ventricular filling pressure was highest in patients in group I and lowest in group III. The greater the restriction in venous return to the left heart, the lower the expected left atrial pressure. The fact that the opposite was seen in this study may reflect the decreased compliance of the left ventricle in chronic pulmonary hypertension, ${ }^{36}$ or, more likely, the difficulty in obtaining an accurate wedged pressure. Decreased compliance may be secondary to the influence of the hypertrophied right ventricle on left ventricular shape and on the mobility of the ventricular septum. ${ }^{2036}$ It is unlikely 
that there is important systolic dysfunction ${ }^{36}$ since left ventricular filling pressure is not raised and a rise in cardiac output follows the use of a pulmonary vasodilator without a change in filling pressure. ${ }^{33} 37$

All three patients who had repeat catheterisation after deterioration showed the expected rise in pulmonary arteriolar resistance and fall in cardiac output. ${ }^{838}$ Pulmonary artery pressure rose only slightly (Fig. 2). The opposite pattern of haemodynamic changes was seen in the three patients in whom symptoms remitted (Fig. 3). The improvement appears to have been independent of initial severity and presentation in right heart failure. The prenylamine and oxygen may have influenced disease progression in case 4. Epoprostenol (prostacyclin) was used in one patient (case 1) as part of a separate study. ${ }^{39}$ This naturally occurring agent can reverse vasoconstriction and prevent platelet deposition and release within the lung bed. ${ }^{40-42}$ One report of long term improvement with continuous epoprostenol infusion, ${ }^{43}$ does not, however, establish that it is more useful than other pulmonary vasodilators, which can also produce long term benefit. ${ }^{44-46}$ Spontaneous regression of pulmonary hypertension in three of our patients suggests that vasolidators, by lowering pulmonary vascular resistance before lung damage is too advanced and pulmonary reactivity is lost, ${ }^{478}$ may reduce pulmonary artery pressure, thereby preventing further deterioration. ${ }^{49}$ Similarly, regression may have occurred in the patient (case 2) in whom pulmonary artery pressure fell as right heart failure occurred. It is more usual for histological changes to advance as lung blood flow falls since this reduction is normally a consequence of right heart failure as pulmonary resistance continues to rise. ${ }^{12}$ Only Heath grade 1 changes were seen at necropsy. Assuming the lung histology was representative, ${ }^{26}$ the two patients with grade 3 changes also had potentially reversible disease. ${ }^{50}$ As we have seen, spontaneous regression occurs, although up to now there have been only four reported cases, ${ }^{6817}$ one of which is in this series. ${ }^{16}$ It seems that pulmonary vascular changes may not always be irreversible even in patients who have clinically advanced disease. Improvement in the clinical state or a fall in pulmonary artery pressure, by whatever means, cannot be equated with regression of pathological changes. This is seen in the fatal case recently reported of a child who died from severe primary pulmonary hypertension but who at necropsy had only relatively mild histological changes in the lung vessels. ${ }^{51}$ In pulmonary hypertension secondary to anorectics, regression is more frequent, ${ }^{46}$ and the prognosis is better. ${ }^{6}$ This is presumably because the onset is recent and the cause is known and removable and this may also apply to patients who present with the disease in pregnancy.

Factors linked to survival were sought. The presence of another member of the family with primary pulmonary hypertension did not predict outcome. There were only two such patients, however, and a systematic search of the families of other probands might have showed more. Familial primary pulmonary hypertension is generally considered to be inherited as an autosomal dominant trait with varying penetrance. ${ }^{29}$ Although all three patients with connective tissue disease survived less than five years, the outcome in these patients was not significantly worse. Death from right heart failure secondary to pulmonary hypertension occurred a considerable time after the appearance of the initial symptoms.

Connective tissue disease is closely linked with Raynaud's phenomenon, and both are associated with primary pulmonary hypertension. ${ }^{211} 12$ There are several ways by which these entities are interconnected. Firstly, all are more frequent in females. Secondly, in Raynaud's disease and Raynaud's phenomenon the lungs and the extremities are affected. Cold stimulation can cause a reduction in the size of the pulmonary capillary bed in patients with Raynaud's disease and early Raynaud's phenomenon. ${ }^{52}$ The likely mechanism of this change is precapillary vasoconstriction, ${ }^{52}$ and implies a generalised mechanism for progressive vascular damage. In scleroderma there is a histological basis for this in that similar changes develop in both digital and pulmonary arteries. ${ }^{53}$ It is not known if patients with Raynaud's disease ever develop primary pulmonary hypertension. Lastly, the lupus anticoagulant, which is associated with an increased risk of spontaneous thrombosis, ${ }^{54}$ is found in some systemic lupus patients with apparently non-embolic pulmonary hypertension. ${ }^{55}$

Because all patients received anticoagulants their role in primary pulmonary hypertension could not be assessed. Recurring small pulmonary thromboemboli, undetected until histology is obtained, are thought by some to contribute to the deterioration seen in patients with primary pulmonary hypertension. ${ }^{27}$ This is far from certain. ${ }^{2}$ Patients might benefit from the prevention of both thrombosis in situ and secondary emboli. Outcome may be improved by the use of anticoagulants. ${ }^{27}$ Antiplatelet and fibrinolytic agents were not used in our series. Disturbance of fibrinolytic ${ }^{5657}$ and platelet function ${ }^{58-61}$ can occur in pulmonary hypertension although the changes may be secondary rather than primary. Nevertheless, such agents could be of benefit, and particularly so in pulmonary hypertension associated with oral contraception ${ }^{1462}$ and 
pregnancy. ${ }^{63}$

Pregnancy at diagnosis seemed to be a favourable prognostic factor. None of the five patients died during a total of eight pregnancies but three of these took place before the onset of symptoms and there was only one further pregnancy after diagnosis. The reported mortality of pregnancy in women with primary pulmonary hypertension is near $50 \%{ }^{1564}$ with a subsequent mean survival of less than five years. ${ }^{15}$ Our cases presented in late pregnancy or after delivery, and reflected the increased load put on the right ventricle at this time. One of the five patients had a patent foramen ovale. She presented during pregnancy but miscarried. Radiography in childhood showed that she had had pulmonary hypertension at least from the age of 12 years. A patent foramen ovale, by permitting right ventricular unloading, may have accounted for her survival. ${ }^{65}$ The favourable outcome for the pregnant group was in part because of spontaneous improvement in two (cases 3 and 4). Prolonged survival after presentation (Table 5) might reflect the onset of symptoms earlier in the disease because of the stress of pregnancy or because of some element of reversibility after pregnancy, if this event had accelerated a vasoconstrictive process.

A patent foramen ovale was associated with longer survival. This is in keeping with the better life expectancy of patients with pulmonary hypertension associated with atrial septal defect than with primary pulmonary hypertension. ${ }^{65}$ Such a shunt, by operating at times of increased demand, permits adequate left ventricular filling and prevents sudden death. ${ }^{910}$ In the absence of a shunt, exercise and systemic vasodilatation may be associated with hypotension and syncope. ${ }^{66}$ The main mechanism for this appears to be inability of the right ventricle to increase its output, perhaps aided by ischaemia secondary to lowered coronary perfusion and increased resistance to right ventricular subendocardial flow. ${ }^{67-69}$ Sudden death frequently occurs in primary pulmonary hypertension and usually in the setting of underlying chronic heart failure. $^{8}$ Surgical creation of an acute shunt by atrial septostomy in a patient with primary pulmonary hypertension was, however, unsuccessful due to the sudden demand put on the left ventricle in the immediate postoperative period. ${ }^{70}$

In conclusion, primary pulmonary hypertension is a heterogeneous disease that often has a better outcome than expected. Prognosis is largely determined by the integrity of the right ventricle. A patent foramen ovale may ameliorate the effect of increased afterload on right ventricular function. Patients in whom the onset of the disease is associated with pregnancy survived longest. Spontaneous regression was more frequent than previously reported and this suggests that early diagnosis and pharmacological treatment of primary pulmonary hypertension may be successful in some patients if the disease is detected early. Methods for such detection and a better understanding of the pathophysiology of the disease are needed.

We thank Mr M Casebow for statistical assistance.

\section{References}

1 Dresdale DT, Schultz M, Michtom RJ. Primary pulmonary hypertension. 1. Clinical and hemodynamic study. Am $\mathcal{F}$ Med 1951; 11: 686-705.

2 Wagenvoort CA, Wagenvoort N. Primary pulmonary hypertension. A pathologic study of the lung vessels in 156 clinically diagnosed cases. Circulation 1970; 42: 1163-84.

3 Loogen F, Both A. Primäre pulmonale hypertonie. $Z$ Kardiol 1976; 65: 1-14.

4 Gurtner HP. Pulmonary hypertension, "plexogenic pulmonary arteriopathy" and the appetite depressant drug aminorex: post or propter? Bull Eur Physiopathol Respir 1979; 15: 897-923.

5 Kanemoto N, Sasamoto H. Pulmonary hemodynamics in primary pulmonary hypertension. $f_{p n}$ Heart $\mathcal{F} 1979$; 20: 395-405.

6 Vob H, Feigel H, Bucking J. Long-term follow-up of primary pulmonary hypertension with and without intake of anorectic drugs. $Z$ Kardiol 1983; 72: 215-21.

7 Watanabe S, Ogata T. Clinical and experimental study upon primary pulmonary hypertension. $\mathfrak{f} p n$ Circ $\mathfrak{f}$ 1976; 40: 603-10.

8 Voelkel N, Reeves JT. Primary pulmonary hypertension. In: Moser KM, ed. Pulmonary vascular diseases. New York: Marcel Dekker, 1979: 573-628.

9 Austen WG, Morrow AG, Berry WB. Experimental studies of the surgical treatment of primary pulmonary hypertension. I Thorac Cardiovasc Surg 1964; 48: 448-55.

10 Grundy SR, Goldfaden DM, Karlson KJ, Jones M, Morrow AG. Prevention of postoperative right ventricular failure by a prosthetic patent foramen ovale [Abstract]. Circulation 1980; 62 (suppl III): 115.

11 Rawson AJ, Woske HM. A study of etiologic factors in so-called primary pulmonary hypertension. Arch Intern Med 1960; 105: 233-43.

12 Walcott G, Burchell HB, Brown AL Jr. Primary pulmonary hypertension. Am f Med 1970; 49: 70-9.

13 Oakley C, Somerville J. Oral contraceptives and progressive pulmonary vascular disease. Lancet 1968; i: 890-3.

14 Kleiger RE, Boxer M, Ingham RE, Harrison DC. Pulmonary hypertension in patients using oral contraceptives. A report of six cases. Chest 1976; 69: 143-7.

15 McCaffrey RM, Dunn LJ. Primary pulmonary hypertension in pregnancy. Obstet Gynecol Surv 1964; 19: 567-91.

16 Bourdillon PDV, Oakley CM. Regression of primary pulmonary hypertension. Br Heart $\mathcal{F} 1976$; 38: 264-70. 
17 Fujii A, Rabinovitch M, Matthews EC. A case of spontaneous resolution of idiopathic pulmonary hypertension. Br Heart $\mathcal{F}$ 1981; 46: 574-7.

18 Wilson AG, Harris CN, Lavender JP, Oakley CM. Perfusion lung scanning in obliterative pulmor.dry hypertension. Br Heart $\mathcal{F}$ 1973; 35: 917-30.

19 Brune J, Emonot A, Wiesendanger T, Munsch C, Galy $P$. Comparative study of alterations of respiratory function tests in chronic pulmonary thromboembolism and primary pulmonary hypertension [Abstract]. Thorax 1979; 34: 697.

20 Goodman DJ, Harrison DC, Popp RL. Echocardiographic features of primary pulmonary hypertension. Am ₹ Cardiol 1974; 33: 438-43.

21 Sokolow M, Lyon TP. The ventricular complex in right ventricular hypertrophy as obtained by unipolar precordial and limb leads. Am Heart $\mathcal{F}$ 1949; 38: 273-94.

22 Shepherd JT, Edwards JE, Burchell HB, Swan HJC, Wood EH. Clinical, physiological, and pathological considerations in patients with idiopathic pulmonary hypertension. Br Heart f 1957; 19: 70-82.

23 Daniel WW. Biostatistics: a foundation for analysis in the health sciences. 2nd ed. New York: John Wiley and Sons, 1978: 402-9.

24 Heath D, Edwards JE. The pathology of hypertensive pulmonary vascular disease. A description of six grades of structural changes in the pulmonary arteries with special reference to congenital cardiac septal defects. Circulation 1958; 18: 533-47.

25 Weir EK. Diagnosis and management of primary pulmonary hypertension. In: Weir EK, Reeves JT, eds. Pulmonary hypertension. New York: Futura Publishing Co, 1984: 115-68.

26 Haworth SG. Primary pulmonary hypertension. $\mathrm{Br}$ Heart $\mathcal{F} \cdot 1983$; 49: 517-21.

27 Fuster V, Steele PM, Edwards WD, Gersh BJ, McGoon MD, Frye RL. Primary pulmonary hypertension: a natural history and the importance of thrombosis. Circulation 1984; 70: 580-7.

28 Thilenius OE, Nadas AS, Jackin H. Primary pulmonary vascular obstruction in children. Pediatrics 1965; 36: 75-87.

29 Loyd JE, Primm RK, Newman JH. Familial primary pulmonary hypertension: clinical patterns. Am Rev Respir Dis 1984; 129: 194-7.

30 Yu PN. Primary pulmonary hypertension: report of six cases and review of literature. Ann Intern Med 1958; 49: 1138-61.

31 Riedel M, Stanek V, Widimsky J, Prerovsky I. Long term follow-up of patients with pulmonary thromboembolism. Late prognosis and evolution of hemodynamic and respiratory data. Chest 1982; 81: 151-8.

32 Kanemoto N, Furuya H, Etoh T, Sasamoto H, Matsuyama $S$. Chest roentgenograms in primary pulmonary hypertension. Chest 1979; 76: 45-9.

33 Arbenz U, Wirz P, Schönbeck M, Gadient A, Mahler F. Wirkung einer acetylcholininfusion auf die hämodynamik bei primär vasculärer pulmonaler hypertonie. Verh Dtsch Ges Inn Med 1971; 77: 1319-21.

34 Stein PD, Sabbah HN, Anbe DT, Marzilli M. Performance of the failing and nonfailing right ventricle of patients with pulmonary hypertension. Am $\mathcal{f}$ Cardiol 1979; 44: 1050-5.

35 Rich S, Martinez J, Lam W, Rosen KM. Captopril as treatment for patients with pulmonary hypertension. Problem of variability in assessing chronic drug treatment. Br Heart f 1982; 48: 272-7.

36 Krayenbuehl HP, Turina J, Hess O. Left ventricular function in chronic pulmonary hypertension. $A m \mathcal{F}$ Cardiol 1978; 41: 1150-8.

37 Pearl RG, Rosenthal MH, Schroeder JS, Ashton JPA. Acute hemodynamic effects of nitroglycerin in pulmonary hypertension. Ann Intern Med 1983; 99: 9-13.

38 Sleeper JC, Orgain ES, McIntosh HD. Primary pulmonary hypertension. Review of clinical features and pathologic physiology with a report of pulmonary haemodynamics derived from repeated catheterization. Circulation 1962; 26: 1358-69.

39 Rozkovec A, Minty K, Stradling J, et al. Value of acute vasodilator studies in management of primary pulmonary hypertension [Abstract]. Circulation 1982; 66 (suppl II): II-49.

40 Steer ML, MacIntyre DE, Levine L, Salzman EW. Is prostacyclin a physiologically important circulating anti-platelet agent? Nature 1980; 283: 194-5.

41 Fitzgerald GA, Brash AR, Farlardeau P, Oates JA. Estimated rate of prostacyclin secretion into the circulation of normal man. $\mathcal{f}$ Clin Invest 1981; 68: 1272-6.

42 Rubin LJ, Groves BM, Reeves JT, Frosolono M, Handel F, Cato AE. Prostacyclin-induced acute pulmonary vasodilation in primary pulmonary hypertension. Circulation 1982; 66: 334-8.

43 Higenbottom T, Wheeldon D, Wells F, Wallwork J. Long-term treatment of primary pulmonary hypertension with continuous intravenous epoprostenol (prostacyclin). Lancet 1984; i: 1046-7.

44 Lupi-Herrera E, Sandoval J, Seaone M, Bialostozky D. The role of hydralazine therapy for pulmonary arterial hypertension of unknown cause. Circulation 1982; 65: 645-50.

45 Rich S, Ganz R, Levy PS. Comparative actions of hydralazine, nifedipine and amrinone in primary pulmonary hypertension. Am $\mathcal{f}$ Cardiol 1983; 52: 1104-7.

46 Rubin LJ, Nicod P, Hillis LD, Firth BG. Treatment of primary pulmonary hypertension with nifedipine. A hemodynamic and scintigraphic evaluation. Ann Intern Med 1983; 99: 433-8.

47 Samet P, Bernstein WH. Loss of reactivity of the pulmonary vascular bed in primary pulmonary hypertension. Am Heart f 1963; 66: 197-9.

48 Reeves JT. Vasodilator therapy for pulmonary hypertension. $N$ Engl f Med 1980; 302: 1261-2.

49 Wagenvoort CA, Nauta J, van der Schaar PJ, Weeda HWH, Wagenvoort N. Effect of flow and pressure on pulmonary vessels. A semi quantitative study based on lung biopsies. Circulation 1967; 35: 1028-37.

50 Heath $\tilde{D}$, Helmholtz HF Jr, Burchell HB, Dushane JW, Kirklin JW, Edwards JE. Relation between structural changes in the small pulmonary arteries and the immediate reversibility of pulmonary hypertension following closure of ventricular and atrial septal defects. Circulation 1958; 18: 1167-74.

51 Juaneda E, Watson H, Haworth SG. An unusual case 
of rapidly progressive primary pulmonary hypertension in childhood. Int $\mathcal{F}$ Cardiol 1985; 7: 306-9.

52 Fahey PJ, Utell MJ, Condemi JJ, Green R, Hyde RW. Raynaud's phenomenon of the lung. Am $\mathcal{F}$ Med 1984; 76: 262-9.

53 Rodnan GP, Myerowitz RL, Justh GO. Morphologic changes in the digital arteries of patients with progressive systemic sclerosis (scleroderma) and Raynaud phenomenon. Medicine (Baltimore) 1980; 59: 393-408.

54 Mueh JR, Herbst KD, Rapaport SI. Thrombosis in patients with the lupus anticoagulant. Ann Intern Med 1980; 92: 156-9.

55 Asherson RA, Mackworth-Young CG, Boey ML, et al. Pulmonary hypertension in systemic lupus erythematosus. $\mathrm{Br} \mathrm{Med} \mathcal{F}$ 1983; 287: 1024-5.

56 Inglesby TV, Singer JW, Gordon DS. Abnormal fibrinolysis in familial pulmonary hypertension. $A m \mathcal{F}$ Med 1973; 55: 5-14.

57 Fuchs J, Mlczoch J, Niessner H, Lechner K. Abnormal fibrinolysis in primary pulmonary hypertension [Abstract]. Eur Heart $\mathcal{F} 1981$; 2: A168.

58 Van Benthuysen KM, Dauber IM, Hyers TA, Steele PP, Weil JV. The role of platelets in hypertensive pulmonary vascular disease [Abstract]. Fed Proc 1981; 40: 794.

59 Kahaleh MB, Osborn I, LeRoy EC. Elevated levels of circulating platelet aggregates and betathromboglobulin in scleroderma. Ann Intern Med 1982; 96: 610-3.

60 Peters AM, Rozkovec A, Bell RN, Hallidie-Smith KA, Goodwin JF, Lavender JP. Platelet kinetics in con- genital heart disease. Cardiovasc Res 1982; 16: 391-7.

61 Nenci GG, Berrettini M, Todisco T, Costantini V, Grasselli S. Exhausted platelets in chronic obstructive pulmonary disease. Respiration 1983; 44: 71-6.

62 Dreyer NA, Pizzo SV. Blood coagulation and idiopathic thromboembolism among fertile women. Contraception 1980; 22: 123-35.

63 Howie PW. Thromboembolism. Clin Obstet Gynecol 1977; 4: 397-417.

64 Nelson DM, Main E, Crafford W, Ahumada GG. Peripartum heart failure due to primary pulmonary hypertension. Obstet Gynecol 1983; 62: 58S-63S.

65 Young D, Mark H. Fate of the patient with the Eisenmenger syndrome. Am f Cardiol 1971; 28: 658-69.

66 Howarth S, Lowe JB. The mechanism of effort syncope in primary pulmonary hypertension and cyanotic congenital heart disease. Br Heart $\mathcal{F}$ 1953; 15: 47-54.

67 James TN. On the cause of syncope and sudden death in primary pulmonary hypertension. Ann Intern Med 1962; 56: 252-64.

68 Vlahakes GJ, Turley K, Hoffman JIE. The pathophysiology of failure in acute right ventricular hypertension: hemodynamic and biochemical correlations. Circulation 1981; 63: 87-95.

69 Gold FL, Bache RJ. Transmural right ventricular blood flow during acute pulmonary artery hypertension in the sedated dog. Evidence for subendocardial ischemia despite residual vasodilator reserve. Circ Res 1982; 51: 196-204.

70 Rich S, Lam W. Atrial septostomy as palliative therapy for refractory primary pulmonary hypertension. $A m \mathcal{F}$ Cardiol 1983; 51: 1560-1. 